\title{
Harmonic Current Compensation Using Constant DC-Capacitor Voltage-Control-Based Strategy of Three-Level Neutral-Point-Clamped Inverter-Based STATCOM with Reactive Power Control
}

\author{
Ayumu Tokiwa* Student Member, Yukiharu Satake* \\ Hiroaki Yamada* Member, Toshihiko Tanaka ${ }^{* a)}$ Fellow \\ Mitsunori Fukuda $^{* *}$ Non-member
}

(Manuscript received June 6, 2018, revised Sep. 13, 2018)

\begin{abstract}
This paper proposes a constant dc-capacitor voltage-control (CDCVC)-based reactive power control strategy of a static synchronous compensator (STATCOM) with a three-level neutral-point-clamped (NPC) inverter, in which the source-side harmonic currents are also compensated. The CDCVC-based reactive power control strategy uses only a CDCVC, which is always used in the grid-connected inverters, STATCOMs etc. Calculation blocks of fundamental active, reactive, and harmonic components are not needed. Thus, the authors offer a simplified strategy for a sourceside reactive power control with source-side harmonic current compensations. The instantaneous power flowing into the STATCOM with a three-level NPC inverter is discussed in detail. The instantaneous power flow shows that using the CDCVC-based strategy for the STATCOM achieves sinusoidal source currents using the controlled source-side reactive power compensating the harmonic currents on the source side. A digital computer simulation is implemented to confirm the validity and high practicability of the CDCVC-based strategy. A reduced-scale prototype experimental model is constructed and tested. The simulation and experimental results demonstrate that sinusoidal source currents are obtained with the CDCVC-based strategy controlling the reactive power on the source side.
\end{abstract}

Keywords: neutral-point-clamped inverter, static synchronous compensator, constant dc-capacitor voltage control, reactive power control, harmonics compensation

\section{Introduction}

Static synchronous compensators (STATCOMs) are now on practical to solve the reactive power interferences. A three-level neutral-point-clamped (NPC) inverter, which was originally proposed by Prof. Nabae, et al. ${ }^{(1)}$, is widely used in industries ${ }^{(2)-(5)}$. The three-level NPC inverter-based STATCOM can be directly connected to the $6,600-\mathrm{Vrms}$ highvoltage distribution feeders. This is a great advantage of the three-level NPC inverter-based STATCOM. For the control strategy of the STATCOMs, the instantaneous activereactive power theory originally proposed by Prof. Akagi, et al. is widely used ${ }^{(6)-(10)}$. Most of this control algorithm is based on instantaneous active-reactive power theory and its extensions for the calculation of reference currents. A synchronous reference frame, decomposition in the time domain of the load currents and theory of instantaneous symmetrical component are also proposed ${ }^{(11)-(13)}$. These reference current calculation methods require a large number of computation steps including transformation blocks. In single-phase

\footnotetext{
a) Correspondence to: Toshihiko Tanaka. E-mail: totanaka@ yamaguchi-u.ac.jp

* Department of Electrical and Electronic Engineering, Yamaguchi University

2-16-1, Tokiwadai, Ube, Yamaguchi 755-8611, Japan

** The Chugoku Electric Manufacturing Company, Incorporated

4-4-32, Minamiku Osu, Hiroshima, Hiroshima 732-8564, Japan
}

three-wire distribution feeders, the present authors proposed a constant dc-capacitor voltage-control (CDCVC)based strategy of the smart charger (SC) for electric vehicles (EVs) that can achieves sinusoidal and balanced source currents with a controlled reactive power on the source side ${ }^{(14)}$.

This paper proposes a CDCVC-based reactive power control strategy for a three-level NPC inverter-based STATCOM, in which the source-side harmonic currents are also compensated. The CDCVC-based reactive power control strategy uses only a CDCVC, which is always used in the gridconnected inverters, STATCOMs etc. Calculation blocks of fundamental active, reactive, and harmonic components are not needed. The authors offer a simplified strategy for a source-side reactive power control with source-side harmonic current compensations. The instantaneous power flowing into the STATCOM with a three-level NPC inverter is discussed in detail. The instantaneous power flow shows that using the CDCVC-based strategy for the STATCOM achieves sinusoidal source currents using the controlled source-side reactive power compensating the harmonic currents on the source side. The simulation and experimental results demonstrate that the sinusoidal source currents are obtained with the CDCVC-based strategy controlling the reactive power on the source side. 


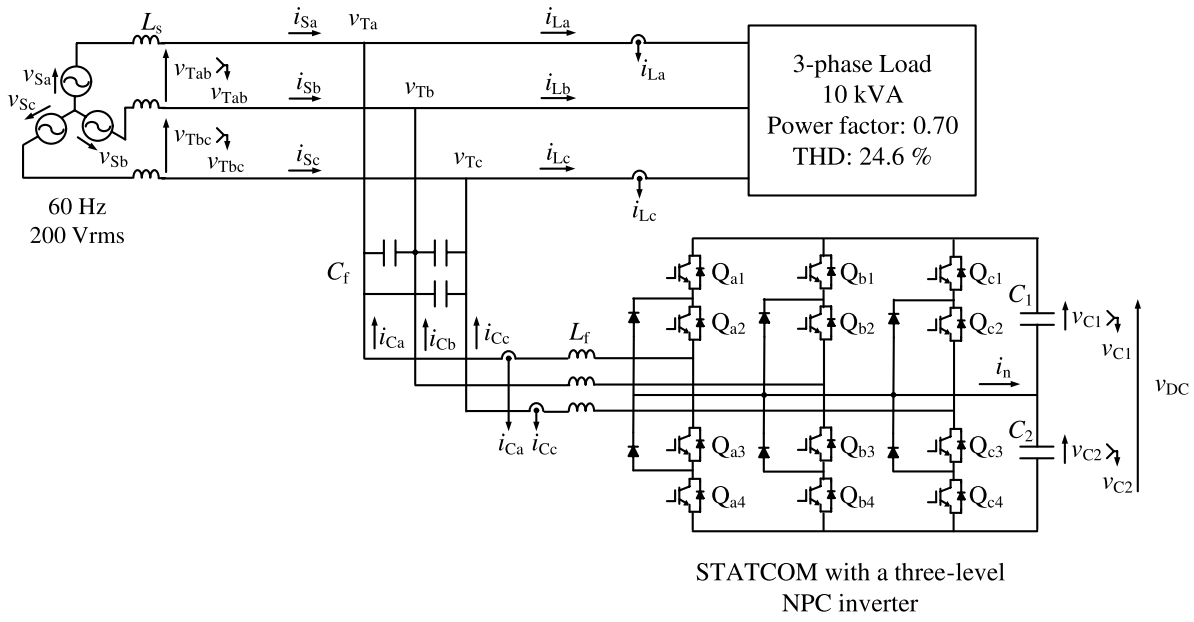

CDCVC-based reactive power control strategy

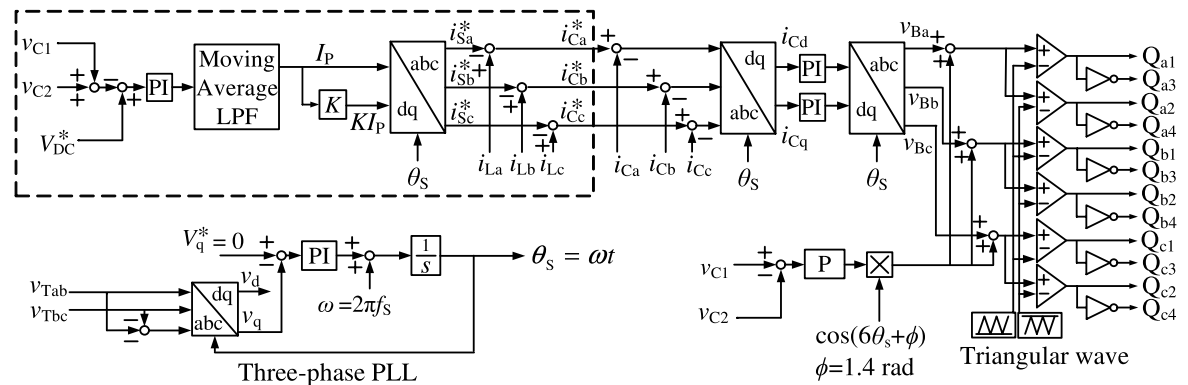

Fig. 1. Circuit diagram of a three-level neutral-point-clamped (NPC) inverter-based static synchronous compensator (STATCOM) with the proposed constant dc-capacitor voltage-control (CDCVC)-based reactive power control strategy

\section{Constant DC-Capacitor Voltage-Control-Based Strategy for Harmonics Compensation with Reactive Power Control}

Figure 1 shows a circuit diagram of a three-level NPC inverter-based STATCOM with the proposed CDCVC-based reactive power control strategy. The part enclosed by the dotted line shows the proposed CDCVC-based reactive power control strategy. The proposed strategy uses only the CDCVC block, which is always used in the grid-connected inverters, STATCOMs etc.

To claim the novelty, simplicity, and practicability of the proposed CDCVC-based reactive power control strategy, the authors, now, compare the proposed strategy to the reactive power control strategy with the instantaneous active-reactive power theory originally proposed by Prof. Akagi, et al. ${ }^{(6)}$. In Figure 1, three-phase terminal voltages $v_{\mathrm{Ta}}, v_{\mathrm{Tb}}$, and $v_{\mathrm{Tc}}$ are expressed as

$$
\begin{aligned}
& v_{\mathrm{Ta}}=\sqrt{2} V_{\mathrm{T}} \cos \omega t, \\
& v_{\mathrm{Tb}}=\sqrt{2} V_{\mathrm{T}} \cos \left(\omega t-\frac{2}{3} \pi\right), \\
& v_{\mathrm{Tc}}=\sqrt{2} V_{\mathrm{T}} \cos \left(\omega t+\frac{2}{3} \pi\right) .
\end{aligned}
$$

Let assume that the three-phase load currents $i_{\mathrm{La}}, i_{\mathrm{Lb}}$, and $i_{\mathrm{Lc}}$ include harmonic currents. The three-phase load currents $i_{\mathrm{La}}, i_{\mathrm{Lb}}$, and $i_{\mathrm{Lc}}$ are expressed as

$$
i_{\mathrm{La}}=\sqrt{2} I_{\mathrm{L} 1} \cos \left(\omega t-\phi_{1}\right)
$$

$$
\begin{aligned}
& +\sqrt{2} \sum_{h=2}^{\infty} I_{\mathrm{L} h} \cos h\left(\omega t-\phi_{1}\right), \\
i_{\mathrm{Lb}}= & \sqrt{2} I_{\mathrm{L} 1} \cos \left(\omega t-\frac{2}{3} \pi-\phi_{1}\right) \\
& +\sqrt{2} \sum_{h=2}^{\infty} I_{\mathrm{L} h} \cos h\left(\omega t-\frac{2}{3} \pi-\phi_{1}\right), \\
i_{\mathrm{Lc}}= & \sqrt{2} I_{\mathrm{L} 1} \cos \left(\omega t+\frac{2}{3} \pi-\phi_{1}\right) \\
& +\sqrt{2} \sum_{h=2}^{\infty} I_{\mathrm{L} h} \cos h\left(\omega t+\frac{2}{3} \pi-\phi_{1}\right) .
\end{aligned}
$$

When the terminal voltages $v_{\mathrm{Ta}}, v_{\mathrm{Tb}}$, and $v_{\mathrm{Tc}}$, and the load currents $i_{\mathrm{La}}, i_{\mathrm{Lb}}$, and $i_{\mathrm{Lc}}$ are transformed into $\alpha-\beta$ coordinates, the instantaneous active power $p$ and instantaneous reactive power $q$ are given by

$$
\left(\begin{array}{c}
p \\
q
\end{array}\right)=\left(\begin{array}{cc}
v_{\mathrm{T} \alpha} & v_{\mathrm{T} \beta} \\
-v_{\mathrm{T} \beta} & v_{\mathrm{T} \alpha}
\end{array}\right)\left(\begin{array}{c}
i_{\mathrm{L} \alpha} \\
i_{\mathrm{L} \beta}
\end{array}\right)
$$

From (3), the three-phase load currents on $\alpha-\beta$ coordinates are decomposed as

$$
\begin{aligned}
i_{\mathrm{L} \alpha}= & \frac{v_{\mathrm{T} \alpha}}{v_{\mathrm{T} \alpha}^{2}+v_{\mathrm{T} \beta}^{2}} \bar{p}+\frac{v_{\mathrm{T} \alpha}}{v_{\mathrm{T} \alpha}^{2}+v_{\mathrm{T} \beta}^{2}} \tilde{p} \\
& -\frac{v_{\mathrm{T} \beta}}{v_{\mathrm{T} \alpha}^{2}+v_{\mathrm{T} \beta}^{2}} \bar{q}-\frac{v_{\mathrm{T} \beta}}{v_{\mathrm{T} \alpha}^{2}+v_{\mathrm{T} \beta}^{2}} \tilde{q},
\end{aligned}
$$




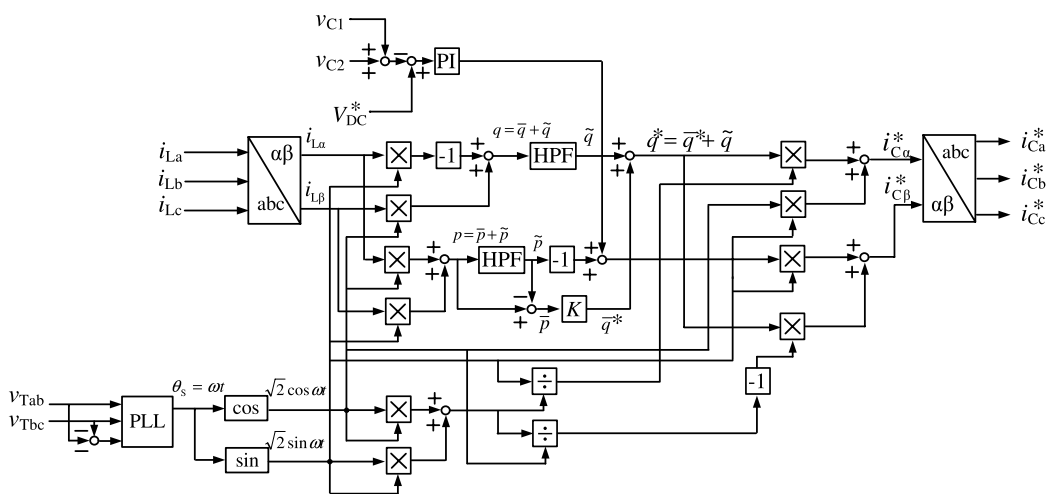

(a)

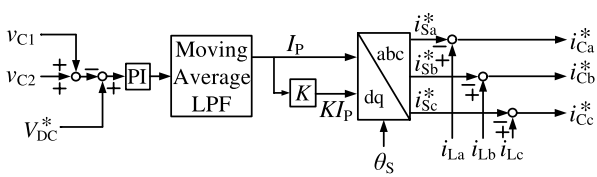

(b)

Fig. 2. Control circuit diagram for STATCOMs. (a) Block diagram of the instantaneous active-reactive power theory-based reactive power control strategy. (b) Block diagram of the proposed CDCVC-based reactive power control strategy, which is the part enclosed by the dotted line in Figure 1

$$
\begin{aligned}
i_{\mathrm{L} \beta}= & \frac{v_{\mathrm{T} \beta}}{v_{\mathrm{T} \alpha}^{2}+v_{\mathrm{T} \beta}^{2}} \bar{p}+\frac{v_{\mathrm{T} \beta}}{v_{\mathrm{T} \alpha}^{2}+v_{\mathrm{T} \beta}^{2}} \tilde{p} \\
& +\frac{v_{\mathrm{T} \alpha}}{v_{\mathrm{T} \alpha}^{2}+v_{\mathrm{T} \beta}^{2}} \bar{q}+\frac{v_{\mathrm{T} \alpha}}{v_{\mathrm{T} \alpha}^{2}+v_{\mathrm{T} \beta}^{2}} \tilde{q},
\end{aligned}
$$

where $\bar{p}$ and $\bar{q}$ are originated in the fundamental components of the load currents in (2) because the terminal voltages in (1) contains the fundamental components, and $\tilde{p}$ and $\tilde{q}$ are originated in the harmonic components in (2). In (4), controlling the dc component $\bar{q}$ on the source side with $\bar{p}$ achieves the reactive power control on the source side.

Figure 2 shows a control circuit diagram for STATCOMs. Figure 2(a) shows a block diagram of the instantaneous active-reactive power theory-based reactive power control strategy. Figure 2(b) shows a block diagram of the proposed CDCVC-based reactive power control strategy, which is the part enclosed by the dotted line in Figure 1. The authors, thus, claim that the simplified source-side reactive power control strategy is offered.

The basic principle of the proposed CDCVC-based reactive power control strategy is, now, discussed in detail. When the harmonic currents of the three-phase load currents $i_{\mathrm{La}}$, $i_{\mathrm{Lb}}$, and $i_{\mathrm{Lc}}$ are compensated on the source side by the STATCOM with the proposed CDCVC-based reactive power control strategy, the three-phase source currents $i_{\mathrm{Sa}}, i_{\mathrm{Sb}}$, and $i_{\mathrm{Sc}}$ are sinusoidal with a controlled reactive power. Three-phase source currents, therefore, can be expressed as

$$
\begin{aligned}
i_{\mathrm{Sa}} & =\sqrt{2} I_{\mathrm{S}} \cos (\omega t-\phi) \\
& =\sqrt{2} I_{\mathrm{P}}(\cos \omega t+K \sin \omega t), \\
i_{\mathrm{Sb}} & =\sqrt{2} I_{\mathrm{S}} \cos \left(\omega t-\frac{2}{3} \pi-\phi\right) \\
& =\sqrt{2} I_{\mathrm{P}}\left\{\cos \left(\omega t-\frac{2}{3} \pi\right)+K \sin \left(\omega t-\frac{2}{3} \pi\right)\right\}, \\
i_{\mathrm{Sc}} & =\sqrt{2} I_{\mathrm{S}} \cos \left(\omega t+\frac{2}{3} \pi-\phi\right) \\
& =\sqrt{2} I_{\mathrm{P}}\left\{\cos \left(\omega t+\frac{2}{3} \pi\right)+K \sin \left(\omega t+\frac{2}{3} \pi\right)\right\}, \cdots
\end{aligned}
$$

where $I_{\mathrm{P}}=I_{\mathrm{S}} \cos \phi$ and $K=\tan \left[\cos ^{-1}\{\right.$ power factor $\left.(\mathrm{PF})\}\right]$. This $I_{\mathrm{P}}$ is the theoretical root-mean-square (RMS) value of the active currents in each phase on the source side, which equal that in each phase on the load side. In Figure 1, the compensation currents $i_{\mathrm{Ca}}, i_{\mathrm{Cb}}$, and $i_{\mathrm{Cc}}$ of the STATCOM with a three-level NPC inverter are given by

$$
\begin{aligned}
& i_{\mathrm{Ca}}=i_{\mathrm{La}}-i_{\mathrm{Sa}}, \\
& i_{\mathrm{Cb}}=i_{\mathrm{Lb}}-i_{\mathrm{Sb}}, \\
& i_{\mathrm{Cc}}=i_{\mathrm{Lc}}-i_{\mathrm{Sc}} .
\end{aligned}
$$

The purpose of this paper is to demonstrate the validity and high practicability of the proposed CDCVC-based harmonic current compensation strategy with reactive power control. Thus, balanced load conditions are considered in this paper. The instantaneous power $p_{\mathrm{c}}$ flowing into the STATCOM is given by

$$
\begin{aligned}
p_{\mathrm{c}}= & v_{\mathrm{Ta}} \cdot i_{\mathrm{Ca}}+v_{\mathrm{Tb}} \cdot i_{\mathrm{Cb}}+v_{\mathrm{Tc}} \cdot i_{\mathrm{Cc}} \\
= & 2 V_{\mathrm{T}}\left\{\frac{3}{2} I_{\mathrm{L} 1} \cos \phi_{1}+\cos \omega t \cdot \sum_{h=2}^{\infty} I_{\mathrm{L} h} \cos h\left(\omega t-\phi_{1}\right)\right. \\
& +\cos \left(\omega t-\frac{2}{3} \pi\right) \cdot \sum_{h=2}^{\infty} I_{\mathrm{L} h} \cos h\left(\omega t-\frac{2}{3} \pi-\phi_{1}\right) \\
& +\cos \left(\omega t+\frac{2}{3} \pi\right) \cdot \sum_{h=2}^{\infty} I_{\mathrm{L} h} \cos h\left(\omega t+\frac{2}{3} \pi-\phi_{1}\right) \\
& \left.-\frac{3}{2} I_{\mathrm{P}}\right\} . \ldots \ldots \ldots \ldots \ldots \ldots \ldots \ldots \ldots \ldots \ldots \ldots \ldots
\end{aligned}
$$

If the mean value of the dc-capacitor voltage $v_{\mathrm{DC}}$ is maintained at constant by the CDCVC in the STATCOM in Figure 1 , the mean value $\bar{p}_{\mathrm{c}}$ of the instantaneous power $p_{\mathrm{c}}$ flowing into the STATCOM should be zero. In (7), thus,

$$
\bar{p}_{\mathrm{c}}=3 V_{\mathrm{T}}\left(I_{\mathrm{L} 1} \cos \phi_{1}-I_{\mathrm{P}}\right) \text {. }
$$

The RMS value $I_{\mathrm{P}}$ of the active currents in each phase on the source side in (5) is given by

$$
I_{\mathrm{P}}=I_{\mathrm{L} 1} \cos \phi_{1} \text {. }
$$

Note that this $I_{\mathrm{P}}$ equals the RMS value of the active currents $I_{\mathrm{P}}=I_{\mathrm{L} 1} \cos \phi_{1}$ on the load side. Thus, it is concluded that the CDCVC of the STATCOM in Figure 1 can calculate the fundamental active current of the load currents $i_{\mathrm{La}}, i_{\mathrm{Lb}}$, and $i_{\mathrm{Lc}}$ in three-phase circuits. In the control circuit block of Figure 1, the dc-capacitor voltages $v_{\mathrm{C} 1}$ and $v_{\mathrm{C} 2}$ are detected. Then, the 


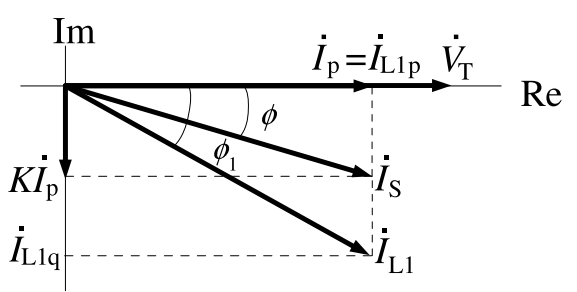

Fig. 3. Per-phase phasor diagram for the terminal voltage $\dot{V}_{\mathrm{T}}$, the source current $\dot{I}_{\mathrm{S}}$, and the load current $\dot{I}_{\mathrm{L}}$

difference between the detected dc-capacitor voltage $v_{\mathrm{C} 1}+$ $v_{\mathrm{C} 2}$ and the reference value $V_{\mathrm{DC}}^{*}$ of the dc-capacitor voltage is amplified by the proportional-integral (PI) controller. A moving-average low-pass filter (LPF) is used to remove the $6 \omega$ angular frequency component, where $\omega$ is the angular frequency of the terminal voltages $v_{\mathrm{Ta}}, v_{\mathrm{Tb}}$, and $v_{\mathrm{Tc}}$. Then, the RMS value $I_{\mathrm{P}}$ of the active currents in each phase is obtained. With the control gain $K$, the RMS value of the fundamental reactive currents on the source side is calculated, where this control gain $K$ can control the reactive power on the source side. Figure 3 shows a per-phase phasor diagram for the terminal voltage $\dot{V}_{\mathrm{T}}$, the source current $\dot{I}_{\mathrm{S}}$, and the load current $\dot{I}_{\mathrm{L}}$. From Figure 3, controlling the control gain $K$ can control the source-side reactive power. The line-to-line voltages $v_{\mathrm{Tab}}$ and $v_{\mathrm{Tbc}}$ are detected, and then, an electrical angle $\theta_{\mathrm{S}}$ is generated using a three-phase phase-locked-loop (PLL) ${ }^{(15)}$. Using this $\theta_{\mathrm{S}}, I_{\mathrm{P}}$, and $K I_{\mathrm{P}}$, the source currents $i_{\mathrm{Sa}}^{*}, i_{\mathrm{Sb}}^{*}$, and $i_{\mathrm{Sc}}^{*}$ with the controlled reactive power in a-b-c coordinates are calculated. Subtracting the calculated $i_{\mathrm{Sa}}^{*}, i_{\mathrm{Sb}}^{*}$, and $i_{\mathrm{Sc}}^{*}$ from the detected load currents $i_{\mathrm{La}}, i_{\mathrm{Lb}}$, and $i_{\mathrm{Lc}}$ gives the reference values $i_{\mathrm{Ca}}^{*}, i_{\mathrm{Cb}}^{*}$, and $i_{\mathrm{Cc}}^{*}$ of the STATCOM. The reference values $i_{\mathrm{Ca}}^{*}, i_{\mathrm{Cb}}^{*}$, and $i_{\mathrm{Cc}}^{*}$ in a-b-c coordinates are given by

$$
\begin{aligned}
& i_{\mathrm{Ca}}^{*}=i_{\mathrm{La}}-i_{\mathrm{Sa}}^{*}, \\
& i_{\mathrm{Cb}}^{*}=i_{\mathrm{Lb}}-i_{\mathrm{Sb}}^{*}, \\
& i_{\mathrm{Cc}}^{*}=i_{\mathrm{Lc}}-i_{\mathrm{Sc}}^{*} .
\end{aligned}
$$

The PI controllers in $d-q$ coordinates are used to control the output currents $i_{\mathrm{Ca}}, i_{\mathrm{Cb}}$, and $i_{\mathrm{Cc}}$. Thus, the differences between the reference values $i_{\mathrm{Ca}}^{*}, i_{\mathrm{Cb}}^{*}$, and $i_{\mathrm{Cc}}^{*}$ and the detected values $i_{\mathrm{Ca}}, i_{\mathrm{Cb}}$, and $i_{\mathrm{Cc}}$ in a-b-c coordinates are transformed into $i_{\mathrm{Cd}}$ and $i_{\mathrm{Cq}}$, respectively. $i_{\mathrm{Cd}}$ and $i_{\mathrm{Cq}}$ are amplified by the PI controllers in $d$ - $q$ coordinates. The amplified differences are retransformed into $a-b-c$ coordinates. It is well known that two dc-capacitor voltages $v_{\mathrm{C} 1}$ and $v_{\mathrm{C} 2}$ are unbalanced ${ }^{(16)}$.

Prof. H. Akagi et al. proposed a voltage-balancing control with the $6^{\text {th }}$-order zero-sequence voltage $\cos \left(6 \theta_{\mathrm{S}}+\phi\right)$ for a three-level NPC inverter ${ }^{(17)}$. The basic principle of the proposed voltage-balancing control was discussed in detail. The experimental results demonstrated that adding $\cos \left(6 \theta_{\mathrm{S}}+\phi\right)$ to the reference values of the three-phase output voltages well balanced two dc-capacitor voltages, where $\phi=1.4 \mathrm{rad}$. In this paper, the $6^{\text {th }}$-order zero-sequence voltage is, thus, added to the reference values of the three-phase output voltages $v_{\mathrm{Ba}}$, $v_{\mathrm{Bb}}$, and $v_{\mathrm{Bc}}$ in Figure 1 . For more detail, see the literature (17). The $6^{\text {th }}$-order zero-sequence voltage is added to the three-phase reference voltages $v_{\mathrm{Ba}}, v_{\mathrm{Bb}}$, and $v_{\mathrm{Bc}}{ }^{(17)}$. A sinetriangle intercept technique is used to generate the gate signals for twelve insulated-gate bipolar transistors (IGBTs).
Table 1. Circuit constants for Figure 1

\begin{tabular}{l|l|l}
\hline Item & Symbol & Value \\
\hline Source inductor & $L_{\mathrm{S}}$ & $0.8 \mathrm{mH}$ \\
\hline Switching inductor & $L_{\mathrm{f}}$ & $1.28 \mathrm{mH}$ \\
\hline Filter capacitor & $C_{\mathrm{f}}$ & $6.0 \mu \mathrm{F}$ \\
\hline Reference dc-capacitor voltage & $V_{\mathrm{DC}}^{*}$ & $400 \mathrm{Vdc}$ \\
\hline DC capacitor & $C_{1}, C_{2}$ & $11200 \mu \mathrm{F}$ \\
\hline Unit capacitance constant & $H$ & $44.8 \mathrm{~ms}$ \\
\hline Carrier frequency & $f_{\mathrm{SW}}$ & $7.2 \mathrm{kHz}$ \\
\hline
\end{tabular}

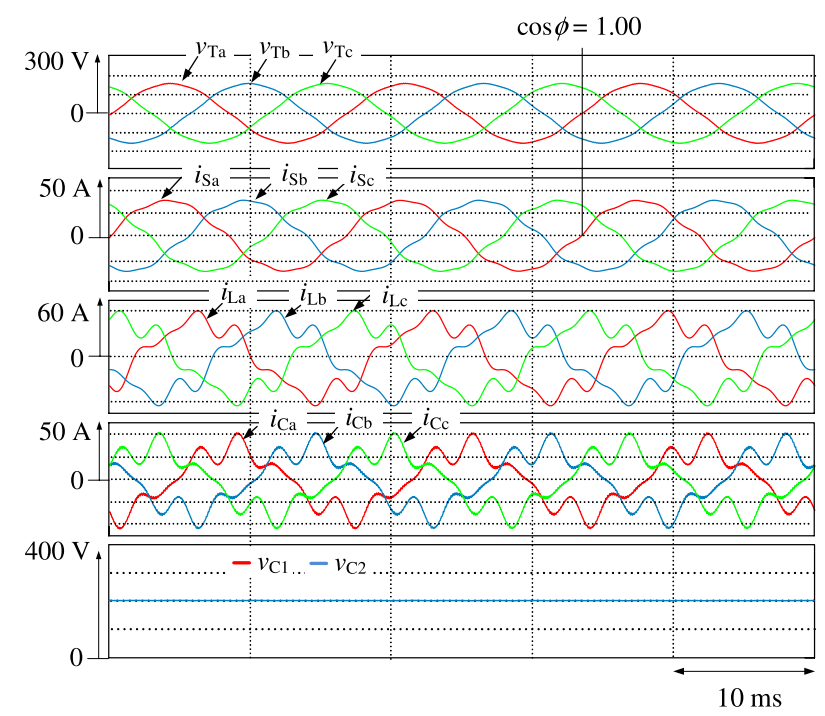

Fig. 4. Simulation waveforms for Figure 1 with the control gain $K=\tan \left\{\cos ^{-1}(\mathrm{PF})\right\}=0$ as shown in Figure 3

\section{Simulation Results}

Digital computer simulation is implemented to confirm the validity and high practicability of the proposed CDCVCbased reactive power control strategy using PSIM software. The three-phase load currents $i_{\mathrm{La}}, i_{\mathrm{Lb}}$, and $i_{\mathrm{Lc}}$ include the $5^{\text {th }}$ - and $7^{\text {th }}$-order harmonic currents in following simulation results. The ratings of three-phase source voltages are $200 \mathrm{Vrms}$ and $60 \mathrm{~Hz}$. The rated three-phase load is $10 \mathrm{kVA}$. Therefore, the RMS value of the fundamental components of the load currents is 28.7 Arms. The $5^{\text {th }}$-order components of 5.7 Arms, which is $20 \%$ as compared to the RMS value of fundamental component, and the $7^{\text {th }}$-order components of 4.1 Arms, which is $14.3 \%$, are also included in the load currents $i_{\mathrm{La}}, i_{\mathrm{Lb}}$, and $i_{\mathrm{Lc}}$. Thus, total harmonic distortion (THD) values of $i_{\mathrm{La}}, i_{\mathrm{Lb}}$, and $i_{\mathrm{Lc}}$ are $24.6 \%$. The PF between the terminal voltages and load currents is 0.70 . Table 1 shows circuit constants for Figure 1, which were used in the following simulation results.

Figure 4 shows simulation results for Figure 1 with the control gain $K=\tan \left\{\cos ^{-1}(\mathrm{PF})\right\}=0$ as shown in Figure 3 . $v_{\mathrm{Ta}}, v_{\mathrm{Tb}}$, and $v_{\mathrm{Tc}}$ are the terminal voltage waveforms and $i_{\mathrm{Sa}}$, $i_{\mathrm{Sb}}$, and $i_{\mathrm{Sc}}$ are the source current waveforms. $i_{\mathrm{La}}, i_{\mathrm{Lb}}$, and $i_{\mathrm{Lc}}$ are load current waveforms; $i_{\mathrm{Ca}}, i_{\mathrm{Cb}}$, and $i_{\mathrm{Cc}}$ are the compensation current waveforms of the STATCOM with the threelevel NPC inverter; and $v_{\mathrm{C} 1}$ and $v_{\mathrm{C} 2}$ are the dc-capacitor voltage waveforms. Although the load currents $i_{\mathrm{La}}, i_{\mathrm{Lb}}$, and $i_{\mathrm{Lc}}$ are distorted with the PF of 0.70 , the source currents $i_{\mathrm{Sa}}, i_{\mathrm{Sb}}$, and $i_{\mathrm{Sc}}$ are sinusoidal with the PF of 1.00. The THD values of $i_{\mathrm{Sa}}, i_{\mathrm{Sb}}$, and $i_{\mathrm{Sc}}$ are $5.8 \%, 5.9 \%$, and $5.8 \%$, respectively. The dc-capacitor voltages $v_{\mathrm{C} 1}$ and $v_{\mathrm{C} 2}$ are well balanced with the method proposed in (17). The ripples of $v_{\mathrm{C} 1}$ and $v_{\mathrm{C} 2}$ are \pm 


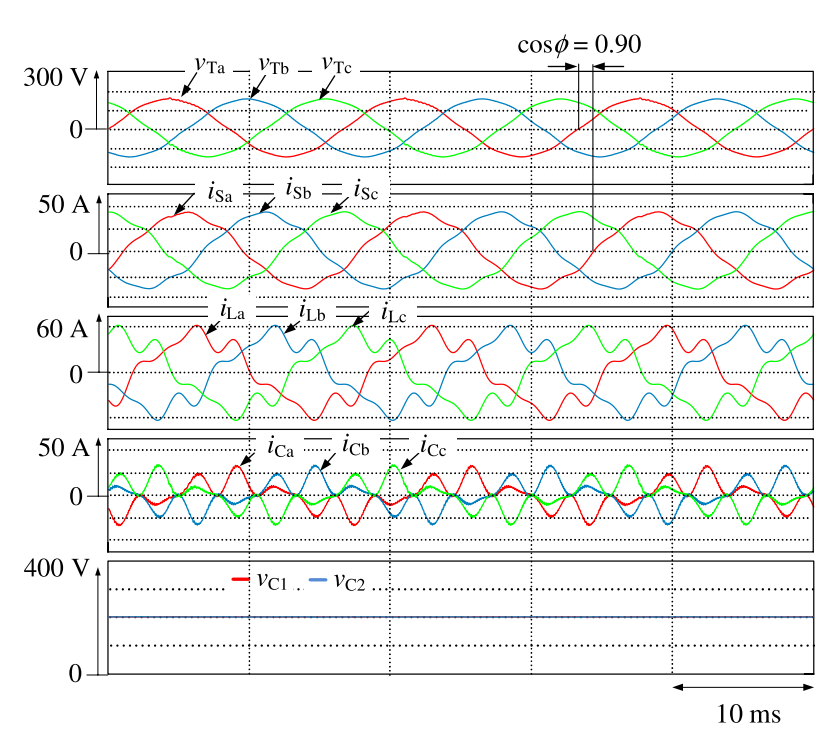

Fig. 5. Simulation waveforms for Figure 1 with the control gain $K=\tan \left\{\cos ^{-1}(\mathrm{PF})\right\}=0.484$ as shown in Figure 3

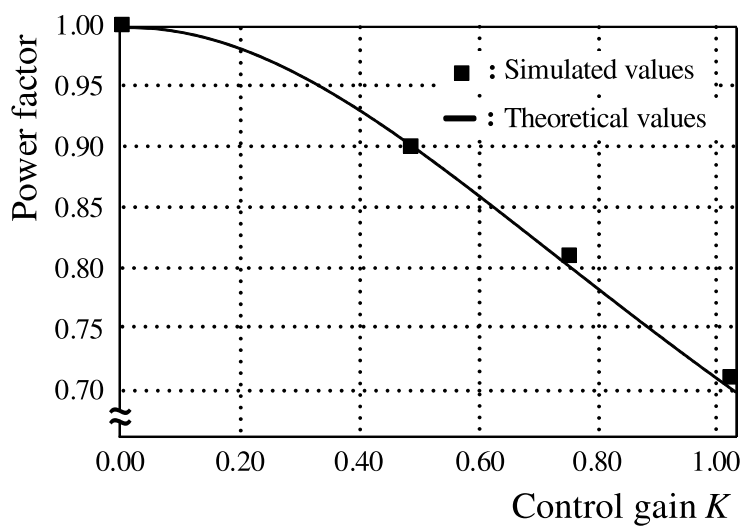

Fig. 6. Theoretical values and simulated values between the control gain $K=\tan \left\{\cos ^{-1}(\mathrm{PF})\right\}$ and the source-side $\mathrm{PF}$

\section{$0.75 \%$, respectively.}

Figure 5 shows simulation results for Figure 1 with the control gain $K=\tan \left\{\cos ^{-1}(\mathrm{PF})\right\}=0.484$ as shown in Figure 3. Although the load currents $i_{\mathrm{La}}, i_{\mathrm{Lb}}$, and $i_{\mathrm{Lc}}$ are distorted with the PF of 0.70 , the source currents $i_{\mathrm{Sa}}, i_{\mathrm{Sb}}$, and $i_{\mathrm{Sc}}$ are sinusoidal with the PF of 0.90 . The THD values of $i_{\mathrm{Sa}}, i_{\mathrm{Sb}}$, and $i_{\mathrm{Sc}}$ are $5.5 \%, 5.6 \%$, and $5.6 \%$, respectively. The dc-capacitor voltages $v_{\mathrm{C} 1}$ and $v_{\mathrm{C} 2}$ are well balanced with the method proposed in (17). The ripples of $v_{\mathrm{C} 1}$ and $v_{\mathrm{C} 2}$ are \pm $0.60 \%$, respectively.

Thus, the CDCVC-based strategy for the STATCOM with a three-level NPC inverter achieves not only the source-side harmonic current compensations but also reactive power control with the proposed CDCVC-based reactive power control strategy.

Figure 6 shows theoretical and simulated values between the control gain $K=\tan \left\{\cos ^{-1}(\mathrm{PF})\right\}$ and the source-side PF. Figure 6 demonstrates that controlling the control gain $K$ can achieve the desired PF on the source side.

\section{Experimental Results}

A prototype experimental model was constructed and tested to demonstrate the validity and high practicability of the proposed control method, which uses only CDCVC for the STATCOM. Figure 7 shows a block diagram of the constructed prototype experimental model. The ratings of three-phase source voltage are $200 \mathrm{Vrms}$ and $60 \mathrm{~Hz}$. Threephase load consists of three-phase diode rectifier and Yconnected inductor. The rated three-phase load is $6.7 \mathrm{kVA}$. The PF between the terminal voltages and load currents is 0.60 , and THD values of $i_{\mathrm{La}}, i_{\mathrm{Lb}}$, and $i_{\mathrm{Lc}}$ are $13.6 \%$. Table 2 shows circuit constants for Figure 7, which were used in the following experimental results. The detected line-to-line voltages $v_{\mathrm{Tab}}$ and $v_{\mathrm{Tbc}}$, load currents $i_{\mathrm{La}}$ and $i_{\mathrm{Lc}}$, compensation currents $i_{\mathrm{Ca}}$ and $i_{\mathrm{Cc}}$, and dc-capacitor voltages $v_{\mathrm{C} 1}$ and $v_{\mathrm{C} 2}$ are fed into a SH microcomputer (SH7216 Renesas Electronics Corp.) through 12 bit A/D converters, where sampling frequency $f_{\mathrm{SW}}$ is $7.2 \mathrm{kHz}$. In the $\mathrm{SH}$ microcomputer, the reference values $i_{\mathrm{Ca}}^{*}, i_{\mathrm{Cb}}^{*}$, and $i_{\mathrm{Cc}}^{*}$ for the NPC inverter, which acts a STATCOM, are calculated by (10). The feedback control in $d$ - $q$ coordinates of Figure 1 is used. This current feedback control is carried out in the $\mathrm{SH}$ microcomputer.

Figure 8 shows experimental results for Figure 7 with the control gain $K=\tan \left\{\cos ^{-1}(\mathrm{PF})\right\}=0$ as shown in Figure 3. $v_{\mathrm{Ta}}$, $v_{\mathrm{Tb}}$, and $v_{\mathrm{Tc}}$ are the terminal voltage waveforms and $i_{\mathrm{Sa}}, i_{\mathrm{Sb}}$, and $i_{\mathrm{Sc}}$ are the source current waveforms. $i_{\mathrm{La}}, i_{\mathrm{Lb}}$, and $i_{\mathrm{Lc}}$ are load current waveforms; $i_{\mathrm{Ca}}, i_{\mathrm{Cb}}$, and $i_{\mathrm{Cc}}$ are the compensation current waveforms of the STATCOM with the NPC inverter; and $v_{\mathrm{C} 1}$ and $v_{\mathrm{C} 2}$ are the dc-capacitor voltage waveforms. Although the load currents $i_{\mathrm{La}}, i_{\mathrm{Lb}}$, and $i_{\mathrm{Lc}}$ are distorted with the PF of 0.60 , the source currents $i_{\mathrm{Sa}}, i_{\mathrm{Sb}}$, and $i_{\mathrm{Sc}}$ are sinusoidal with the PF of 1.00. The THD values of $i_{\mathrm{Sa}}, i_{\mathrm{Sb}}$, and $i_{\mathrm{Sc}}$ are $9.0 \%, 9.0 \%$, and $8.9 \%$, respectively. The dc-capacitor voltages $v_{\mathrm{C} 1}$ and $v_{\mathrm{C} 2}$ are well balanced with the method proposed in (17).

Figure 9 shows experimental results for Figure 7 with the control gain $K=\tan \left\{\cos ^{-1}(\mathrm{PF})\right\}=0.484$ as shown in Figure 3 . Although the load currents $i_{\mathrm{La}}, i_{\mathrm{Lb}}$, and $i_{\mathrm{Lc}}$ are distorted with the PF of 0.60 , the source currents $i_{\mathrm{Sa}}, i_{\mathrm{Sb}}$, and $i_{\mathrm{Sc}}$ are sinusoidal with the PF of 0.90 . The THD values of $i_{\mathrm{Sa}}, i_{\mathrm{Sb}}$, and $i_{\mathrm{Sc}}$ are $8.1 \%, 8.5 \%$, and $8.6 \%$, respectively. The dc-capacitor voltages $v_{\mathrm{C} 1}$ and $v_{\mathrm{C} 2}$ are well balanced with the method proposed in (17). Thus, the CDCVC-based strategy for the STATCOM with a three-level NPC inverter achieves not only the source-side harmonic current compensations but also reactive power control with the proposed CDCVC-based reactive power control strategy. The experimental results of Figure 8 and Figure 9 are in good agreement with the simulation results of Figure 4 and Figure 5.

\section{Conclusion}

This paper has proposed a CDCVC-based reactive power control strategy of a STATCOM with a three-level NPC inverter, in which the source-side harmonic currents are also compensated. The CDCVC-based reactive power control strategy uses only a CDCVC, which is always used in the grid-connected inverters, STATCOMs etc. Calculation blocks of fundamental active, reactive, and harmonic components are not needed. The authors offer a simplified strategy for the source-side reactive power control with the sourceside harmonic current compensations. The instantaneous power flowing into the STATCOM with a three-level NPC inverter has been discussed in detail. The instantaneous 


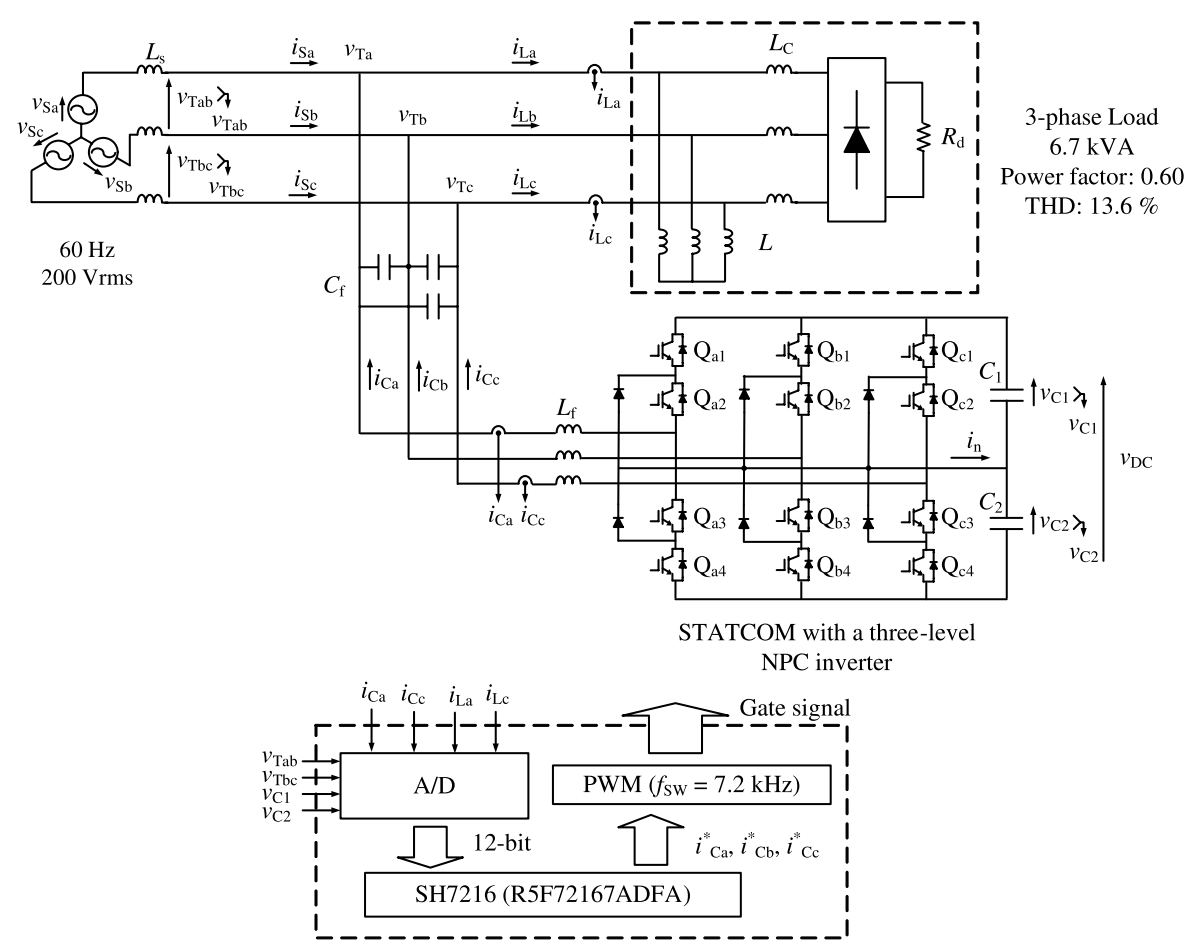

Fig. 7. Brock diagram of constructed experimental model for STATCOM with three-level NPC inverter in Figure 1

Table 2. Circuit constants for Figure 7

\begin{tabular}{l|l|l}
\hline Item & Symbol & Value \\
\hline Switching inductor & $L_{\mathrm{f}}$ & $1.28 \mathrm{mH}$ \\
\hline Filter capacitor & $C_{\mathrm{f}}$ & $6.0 \mu \mathrm{F}$ \\
\hline Reference dc-capacitor voltage & $V_{\mathrm{DC}}^{s}$ & $400 \mathrm{Vdc}$ \\
\hline DC capacitor & $C_{1}, C_{2}$ & $11200 \mu \mathrm{F}$ \\
\hline Unit capacitance constant & $H$ & $44.8 \mathrm{~ms}$ \\
\hline Carrier frequency & $f_{\mathrm{SW}}$ & $7.2 \mathrm{kHz}$ \\
\hline Inductor & $L$ & $20 \mathrm{mH}$ \\
\hline $\begin{array}{l}\text { DC-side resistor of } \\
\text { three-phase diode rectifier }\end{array}$ & $R_{\mathrm{d}}$ & $16.7 \Omega$ \\
\hline $\begin{array}{l}\text { AC-side inductor of } \\
\text { three-phase diode rectifier }\end{array}$ & $L_{\mathrm{C}}$ & $1.2 \mathrm{mH}$ \\
\hline
\end{tabular}

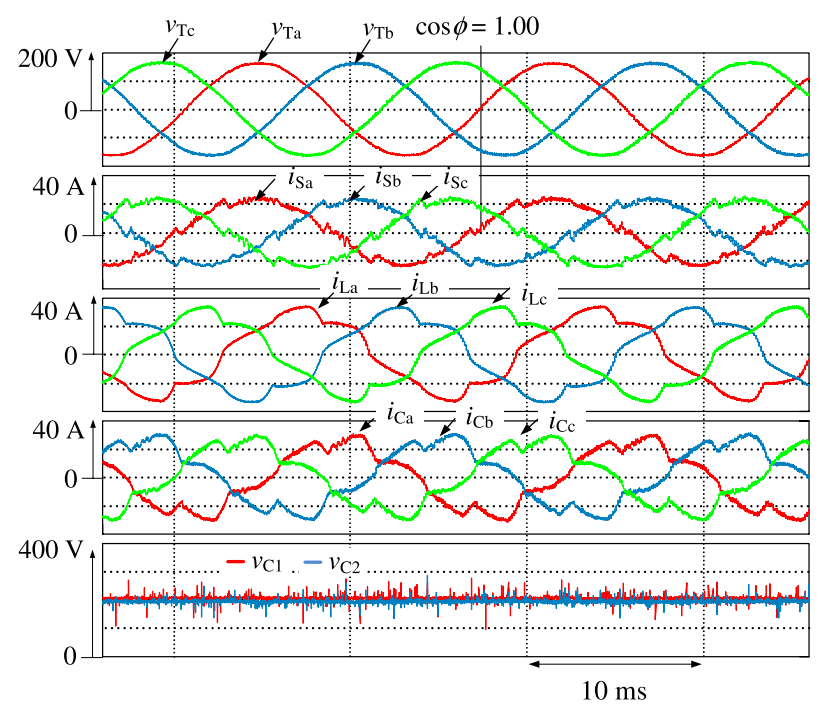

Fig. 8. Experimental waveforms for Figure 7 with the control gain $K=\tan \left\{\cos ^{-1}(\mathrm{PF})\right\}=0$ as shown in Figure 3

power flow shows that using the CDCVC-based strategy for the STATCOM achieves sinusoidal source currents using the

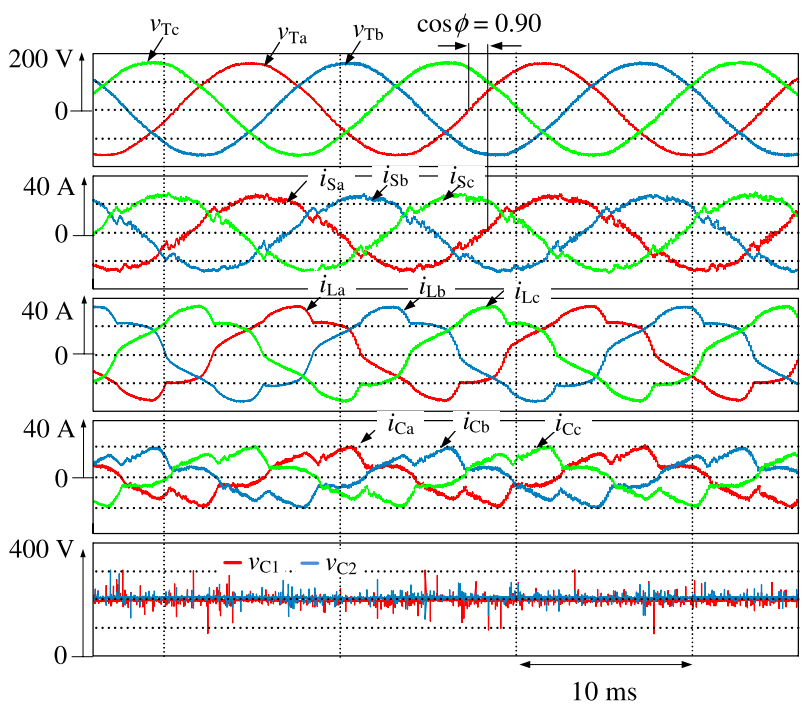

Fig. 9. Experimental waveforms for Figure 7 with the control gain $K=\tan \left\{\cos ^{-1}(\mathrm{PF})\right\}=0.484$ as shown in Figure 3

controlled source-side reactive power compensating the harmonic currents on the source side. A digital computer simulation has been implemented to confirm the validity and high practicability of the CDCVC-based strategy. A reducedscale prototype experimental model has been constructed and tested. The simulation and experimental results have demonstrated that the sinusoidal source currents are obtained with the CDCVC-based strategy controlling the reactive power on the source side.

In this paper, balanced load conditions have been considered to demonstrate the validity and high practicability of the proposed CDCVC-based harmonic current compensation strategy with reactive power control. The compensation 
performance of the proposed CDCVC-based strategy of the three-level NPC inverter-based STATCOM under unbalanced load conditions is a next issue for further study. This will be reported in another article.

\section{References}

(1) A. Nabae, I. Takahashi, and H. Akagi: "A new neutral-point-clamped PWM inverter", IEEE Trans. Ind. Appl., Vol.IA-17, No.5, pp.518-523 (1981)

( 2 ) J. Steinke: "Switching frequency optimal PWM control of a three-level inverter", IEEE Trans. Power Electron., Vol.7, No.3, pp.487-496 (1992)

( 3 ) R. Rojas, T. Ohnishi, and T. Suzuki: "An improved voltage vector control method for neutral-point-clamped inverters", IEEE Trans. Power Electron., Vol.10, No.6, pp.666-672 (1995)

( 4 ) G.C. Cho, G.H. Jung, N.S. Choi, and G.H. Cho: "Analysis and controller design of static var compensator using three-level GTO inverter", IEEE Trans. Power Electron., Vol.11, No.1, pp.57-65 (1996)

( 5 ) Y.H. Lee, B.S. Suh, and D.S. Hyun: "A novel PWM scheme for a three-level voltage source inverter with GTO thyristors", IEEE Trans. Ind. Appl., Vol.32, No.2. pp.260-268 (1996)

( 6 ) H. Akagi, Y. Kanazawa, and A. Nabae: "Instantaneous reactive power compensators comprising switching devices without energy storage components", IEEE Trans. Ind. Appl., Vol.IA-20, No.3, pp.625-630 (1984)

( 7 ) F.Z. Peng, G.W. Ott, and D.J. Adams: "Harmonic and reactive power compensation based on the generalized instantaneous reactive power theory for the three-phase four-wire systems", IEEE Trans. Power Electron., Vol.13, No.6, pp.1174-1181 (1998)

( 8 ) A. Nava-Segura and G. Mino-Aguilar: "Four-branches-inverter-based-activefilter for unbalanced 3-phase 4-wires electrical distribution systems", Proc. IEEE Trans. Ind. Appl. Conf., Vol.4, No.3, pp.2503-2508 (2000)

( 9 ) B.N. Singh and P. Rast: "A new topology of active filter to correct powerfactor, compensate harmonics, reactive power and unbalance of three-phase four-wire loads", IEEE Appl. Power Electron. and Expo., Vol.1, pp.141-147 (2003)

(10) A. Adya, A.P. Mittal, and J.R.P. Gupta: "Modeling and control of DSTATCOM for three-phase four-wire distribution systems", in Conf. Rec. of the 40th IEEE-IAS Annu. Meet., Hong Kong, China, pp.2428-2434 (2005)

(11) J.W. Dixon, J.J. Garcia, and I. Moran: "Control system for three-phase active power filter which simultaneously compensates power factor and unbalanced loads", IEEE Trans. Ind. Electron., Vol.42, No.6, pp.636-641 (1995)

(12) A. Abllan, G. Garcera, M. Pascual, and E. Figueres: "A new current controller applied to four-branch inverter shunt active filters with UPF control method", Proc. of PESC' 01, Vol.3, pp.1402-1407 (2001)

(13) N. Geddada, S.B. Karanki, M.K. Mishra, and B.K. Kumar: "Modified four leg DSTATCOM topology for compensation of unbalanced and nonlinear loads in three phase four wire system", Proc. of EPE' 11, pp.1-10 (2011)

(14) H. Tanaka, F. Ikeda, T. Tanaka, H. Yamada, and M. Okamoto: "Novel reactive power control strategy based on constant dc-capacitor voltage control for reducing the capacity of smart charger for electric vehicles on single-phase three-wire distribution feeders", IEEE Journal of Emerging and Selected Topics in Power Electronics, Vol.4, No.2, pp.481-488 (2016)

(15) L.N. Arruda, S.M. Silva, and B.J. C Filho: "PLL structure for utility connected systems", in Conf. Rec. of the 36th IEEE-IAS Annu. Meet., Chicago, USA, pp.2655-2660 (2001)

(16) S. Ogasawara and H. Akagi: "Analysis of variation of neutral point potential in neutral-point-clamped voltage source PWM inverters", in Proc. IEEE Ind. Appl. Soc. Conf. Rec., pp.965-970 (1993)

(17) R. Kondo and H. Akagi: "Voltage-balancing control of three-level PWM converter in a transformerless hybrid active filter", IEEJ Trans. IA, Vol.128, No.12, pp.1388-1395 (2008)

(Student Member) received the B.E. and M.E. degrees in electrical engineering from Yamaguchi University in 2016 and 2017, respectively. He is currently working toward the Ph.D. degree in engineering. He is engaged in research on static synchronous compensator. He is a student member of the IEEE.
Yukiharu Satake (Student Member) received the B.E. degrees in

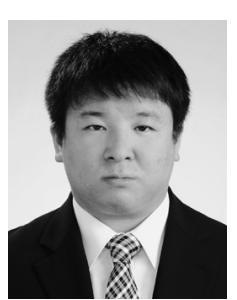
electrical engineering from Yamaguchi University in 2018. He is currently working toward the M.E. degree in electrical engineering. He is engaged in research on static synchronous compensator.

Hiroaki Yamada (Member) received the M.E. degree from Shimane

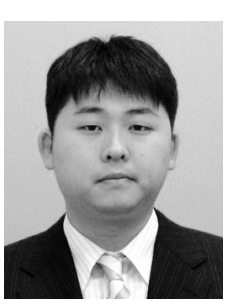
University in 2004. In 2007, he received the Doctor of Engineering from Yamaguchi University. From 2007 to 2010, he was a Lecturer at Kushiro National College of Technology. From 2010 to 2014, he was an Assistant Professor at Kyushu Institute of Technology. Since 2014, he has been a Lecturer in the Department of Electrical and Electronic Engineering at Yamaguchi University. His research interests include power conversion systems for LED driver and wind power generation system. Dr. Yamada is a member of the IEEE.

Toshihiko Tanaka (Fellow) was born in Hokkaido, Japan, in 1959.

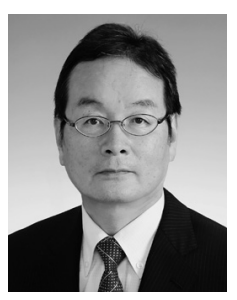
He received the M.E. degree from Nagaoka University of Technology in 1984. In 1995, he received the Ph.D. degree in Engineering from Okayama University, Japan. He joined Toyo Denki Mfg. Co. in 1984. From 1991 to 1997, he was an Assistant Professor at the Polytechnic University of Japan. From 1997 to 2004, he was an Associate Professor at Shimane University. Since 2004, he has been a Professor in the Department of Electrical and Electronic Engineering at Yamaguchi University. His research interests are on harmonics generated by static power converters and their compensation. Dr. Tanaka is a member of the IEEE.

Mitsunori Fukuda (Non-member) received the B.E. degrees in elec-

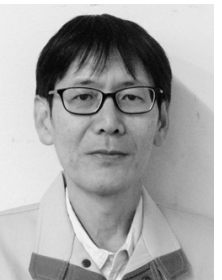
trical and communication engineering from Tokyo Denki University in 1989. He joined the Chugoku Electric Manufacturing, Company, Incorporated in 1993. Since 2012, he has been a section manager in the Chugoku Electric Manufacturing, Company, Incorporated. He is engaged in development of powersystem supervisory control systems and static var compensators.

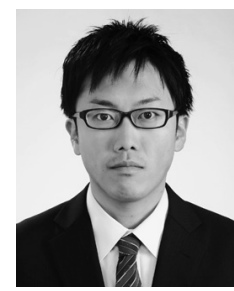

